\title{
Failure analysis of adhesively bonded structures: from coupon level data to structural level predictions and verification
}

\author{
DE XIE ${ }^{1}$, JAEUNG CHUNG ${ }^{1}$, ANTHONY M. WAAS ${ }^{1, *}$, KHALED W. \\ SHAHWAN ${ }^{2}$, JESSICA A. SCHROEDER ${ }^{3}$, RAYMOND G. BOEMAN, $^{4}$ \\ VLASTIMIL KUNC ${ }^{4}$ and LYNN B. KLETT ${ }^{4}$ \\ ${ }^{1}$ Department of Aerospace Engineering, The University of Michigan, Ann Arbor, MI 48109-2140, USA \\ ${ }^{2}$ Scientific Labs, DaimlerChrysler Corporation, Auburn Hills, MI 48326-2757, USA \\ ${ }^{3}$ Research and Development Center, General Motors Corporation, Warren, MI 48090-9055, USA \\ ${ }^{4}$ Metals and Ceramics Division, Oak Ridge National Laboratory, Oak Ridge, TN 37831-6053, USA \\ *Author for correspondence. (E-mail: dcw@umich.edu;)
}

Received 29 December 2004; accepted 6 July 2005

\begin{abstract}
This paper presents a predictive methodology and verification through experiment for the analysis and failure of adhesively bonded, hat stiffened structures using coupon level input data. The hats were made of steel and carbon fiber reinforced polymer composite, respectively, and bonded to steel adherends. A critical strain energy release rate criterion was used to predict the failure loads of the structure. To account for significant geometrical changes observed in the structural level test, an adaptive virtual crack closure technique based on an updated local coordinate system at the crack tip was developed to calculate the strain energy release rates. Input data for critical strain energy release rates as a function of mode mixity was obtained by carrying out coupon level mixed mode fracture tests using the Fernlund-Spelt (FS) test fixture. The predicted loads at failure, along with strains at different locations, were compared with those measured from the structural level tests. The predictions were found to agree well with measurements for multiple replicates of adhesively bonded hat-stiffened structures made with steel hat/adhesive/steel and composite hat/adhesive/steel, thus validating the proposed methodology for failure prediction.
\end{abstract}

Key words: Adhesively bonded structures, failure analysis, fracture toughness of adhesive, mixed-mode fracture envelope, strain energy release rates, virtual crack closure technique.

\section{Introduction}

To develop and demonstrate design technology required to ascertain production-feasible and safety-reliable composite materials in vehicles, it is essential for the automotive and aerospace industries to determine the stiffness and strength of adhesively bonded assemblies made of such materials. The estimation of stiffness is fairly well developed (Xiao et al., 2004a, b). However, the prediction of failure strength is less mature. The strength of an adhesively bonded structure is dictated by a variety of factors, including surface preparation and surface chemistry in addition to the mechanical properties of the constituents. Demonstrating damage tolerance is an important consideration in the design and development of an adhesively bonded structure (Atluri, 1997). In the present paper, the effect of damage, in the form of an initial crack placed between the adhesive layer and the substrate (the flat steel sheet), on the strength of the bonded assembly is 


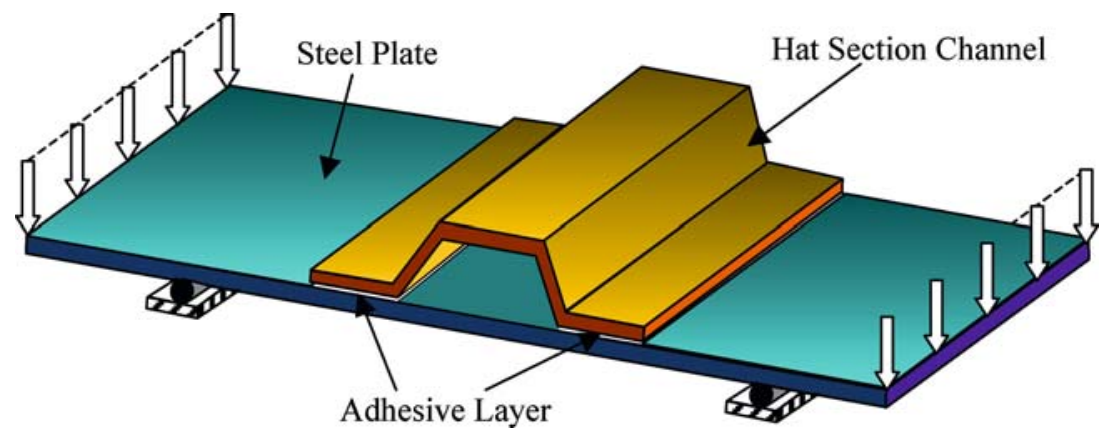

Figure 1. Configuration of the adhesively bonded hat structure.

investigated and a fracture mechanics based methodology is developed to assess structural integrity. Figure 1 shows the configuration of the hat stiffened adhesively bonded structure (HABS) studied.

In fracture mechanics, the initiation of failure from a pre-existing crack is evaluated by comparing an appropriate calculated fracture mechanics parameter of the structure with its measured critical value through tests conducted at the coupon level. Therefore, fracture mechanics based methodology has three basic elements (1) calculation of the fracture parameter; (2) measurement of the critical values of that fracture parameter; and (3) application of a proper fracture criterion that relates the values of the computed fracture parameter to the measured fracture parameter in order to determine failure initiation in the structure. For the present study, the strain energy release rate $(G)$ was selected as the fracture parameter.

Existing closed-form solutions for strain energy release rates are limited to idealized joints (Suo and Hutchinson, 1990; Hutchinson and Suo, 1992; Bao et al., 1992) and not applicable to the present hat structure that exhibits non-linear material behavior and non-linear geometric effects when subjected to mechanical load. Therefore, the virtual crack closure technique (VCCT) (Rybicki and Kanninen, 1977; Shivakumar et al., 1988; Krueger, NASA/Cr-2002-211628; Xie and Biggers (accepted, submitted) was used to calculate the strain energy release rate for the structure in conjunction with a finite element analysis (FEA). To accommodate geometric nonlinearity, a local coordinate system was attached to the crack tip and used in conjunction with an adaptive VCCT. Since the embedded crack had the possibility of turning into the adhesive, a kinking VCCT was needed (Xie et al., 2004). An interfacial element was developed to allow implementation of the adaptive kinking VCCT into the commercial FEA software ABAQUS ${ }^{\circledR}$, with a user subroutine (UEL), so that strain energy release rates could be calculated simultaneously with the stress analysis that was also carried out using ABAQUS ${ }^{\circledR}$ without additional postprocessing.

The fracture envelope $\left(G_{\mathrm{C}}\right.$ vs. $\left.\psi\right)$ of the joint was measured through the use of adhesive joint coupons (Chung and Wass, 2002). The initial crack was artificially created along the adhesive/steel substrate interface by embedding Telfon ${ }^{\circledR}$ tape at the end of the adhesive bead. Due to the wide range of loading possibilities encountered in practice, joint coupons needed to be tested under mixed mode $(\psi)$ loading cases to obtain a complete fracture envelope. The Fernlund and Spelt (FS) fixture was used to generate different mode mixities (Fernlund and Spelt, 1994a, b; Papini et al., 1994). 
In the hat-stiffened structure, the crack could either initiate and grow along the interface as embedded or turn into the adhesive (Reeder and Crews, 1990; Wang and Suo, 1990; Swadener et al., 2002). By using the local mode I $\left(G_{\mathrm{I}}\right)$ dominance as shown in Xie et al. (2005), the crack was predicted to extend along the interface. This was confirmed by the structural level tests. By comparing the calculated ( $G$ vs. $\psi$ ) curve with the fracture envelope $\left(G_{\mathrm{C}}\right.$ vs. $\left.\psi\right)$ of the interface, the failure strength was predicted for both the steel HABS and the composite HABS. The predicted loads were compared against those measured from the full scale tests. The strains at different locations were also compared to verify the accuracy of the FEA model. The results were found be in very good agreement. The results provided in this paper substantiate and verify the analysis and testing procedure introduced here for the design of adhesively bonded structures.

\section{Interface element for VCCT}

There is no analytical solution available for the HABS to calculate the strain energy release rates $\left(G_{\mathrm{I}}\right.$ and $\left.G_{\mathrm{II}}\right)$ in explicit form. However, they can be calculated by the VCCT in conjunction with a finite element stress analysis. To apply the approach efficiently, an interface element was developed based on a one-step VCCT analysis proposed by Rybicki and Kanninen (1977). Figure 2 shows the element definition and node numbering. In order to calculate the nodal forces at the crack tip, a very stiff spring is placed between nodes " 1 " and " 2 ", and nodes " 3 " and "4", respectively. Nodes 5, 6, 7, 8 are "dummy" nodes and do not contribute to the stiffness matrix. They are introduced to extract information for displacement opening behind the crack tip and the crack jump length ahead of the crack tip. Details about the VCCT interface element and its applications to crack growth and crack kinking can be found in References (Xie and Biggers, accepted, submitted; Xie et al., 2004).

In the present problem, large crack tip rotations suggest an adaptive VCCT which can account for the rotation of the local coordinate system placed at the crack tip. The instantaneous local coordinate system $(\bar{X}, \bar{Y})$ can be determined by the relative position between nodes "1" and "9"; that is, with respect to Figure 2,

$$
\cos \theta=\frac{x_{9}-x_{1}}{\Delta a} ; \quad \sin \theta=\frac{y_{9}-y_{1}}{\Delta a}
$$

where, the virtual crack length $\Delta a=\sqrt{\left(x_{9}-x_{1}\right)^{2}+\left(y_{9}-y_{1}\right)^{2}}$

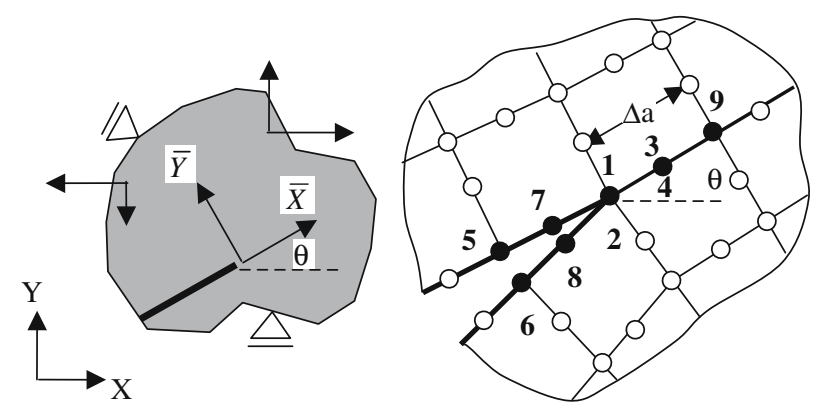

Figure 2. Interface element for slant crack lying in $(X, Y)$ plane. 
Then the nodal forces and the displacement openings are projected onto the local coordinate system $(\bar{X}, \bar{Y})$ as

$$
\left\{\begin{array}{l}
\bar{F}_{x}=F_{x} \cos \theta+F_{y} \sin \theta \\
\bar{F}_{y}=-F_{x} \sin \theta+F_{y} \cos \theta
\end{array}\right.
$$

and

$$
\left\{\begin{array}{l}
\Delta \bar{u}=\Delta u \cos \theta+\Delta v \sin \theta \\
\Delta \bar{v}=-\Delta u \sin \theta+\Delta v \cos \theta
\end{array}\right.
$$

The strain energy release rates are calculated using the expressions,

$$
\begin{aligned}
& G_{\mathrm{I}}=\frac{1}{2 B \Delta a}\left(\bar{F}_{y 12} \Delta \bar{v}_{56}+\bar{F}_{y 34} \Delta \bar{v}_{78}\right) \\
& G_{\mathrm{II}}=\frac{1}{2 B \Delta a}\left(\bar{F}_{x 12} \Delta \bar{u}_{56}+\bar{F}_{x 34} \Delta \bar{u}_{78}\right)
\end{aligned}
$$

where $B$ is the width of the cracked body. However, these modifications are not valid in crack kinking problems since a kinking crack is associated with non self-similar growth. The kinking VCCT was developed by Xie et al. (2004). The instantaneous coordinates " $\mathbf{x}$ " are updated by adding the displacements "u" onto the original coordinates " $\mathbf{X}^{\mathbf{0}}$ " as

$$
\mathbf{x}=\mathbf{X}^{\mathbf{0}}+\mathbf{u}
$$

The adaptive VCCT interface element has been implemented in the commercial FEA software ABAQUS ${ }^{\circledR}$ so that the strain energy release rates for the embedded interfacial cracks of HABS can be obtained simultaneously as ABAQUS ${ }^{\circledR}$ performs conventional finite element analysis on the hat structure. The strain energy release rates are directly computed through ABAQUS ${ }^{\circledR}$ state variables ("SDVs"), without extra post-processing. The element was validated by comparison with an existing analytical solution available in Bao et al. (1992).

\section{Fracture envelope using adhesively bonded coupons}

In this section, the details of the tests done to generate the fracture envelope are provided. The FS fixture was adopted to generate different mixed mode loading conditions at the crack tip. The specimens were adhesively bonded double cantilever beams (DCBs). The dimensions of the test specimens are shown in Figure 3. As seen in Figure 3, the test specimens consist of two adherends (made of steel) and an adhesive layer. The properties of the material are shown in Table 1. A typical test specimen had an embedded starter crack of $25.4 \mathrm{~mm}$ which was made by attaching a $25.4 \mathrm{~mm}$ long pressure sensitive Teflon ${ }^{\circledR}$ film tape. As seen in Figure 3, the actual crack lengths were reduced due to the required space for the grips to hold the test specimens. The actual crack sizes, then, were $12.70 \mathrm{~mm}$.

To obtain a reasonably complete fracture envelope, four tests were performed to generate pure mode I, pure Mode II and mixed-mode loading at the crack tip. Figure 4 shows the experimental setup used in this work. The double-cantilever-beam 

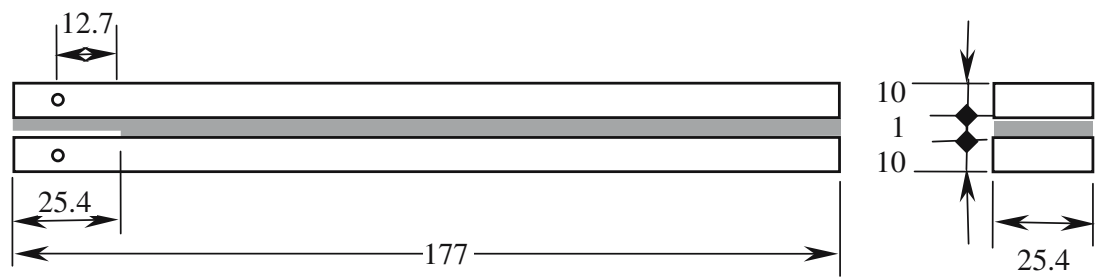

(unit: $\mathrm{mm}$ )

Figure 3. Configuration and dimensions of DCB type coupons used to obtain fracture envelope.

Table 1. Mechanical properties.

\begin{tabular}{lll}
\hline Material & $\begin{array}{l}\text { Young's modulus, } \\
E(\mathrm{MPa})\end{array}$ & $\begin{array}{l}\text { Poisson's } \\
\text { ratio, } v\end{array}$ \\
\hline Steel & 207000 & 0.285 \\
Adhesive & 3694.9 & 0.35 \\
\hline
\end{tabular}

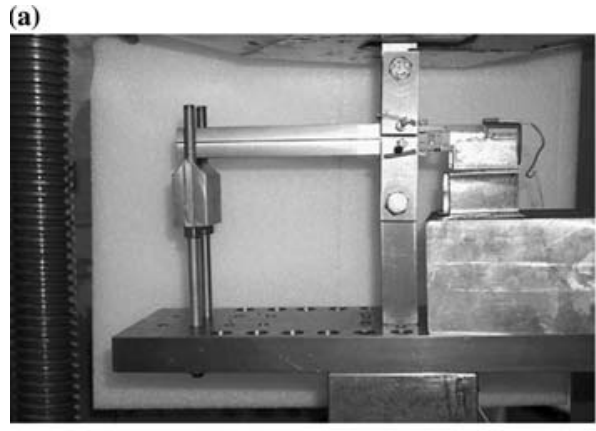

DCB $\left(\right.$ mode I, $\left.\psi=0^{\circ}\right)$

(c)

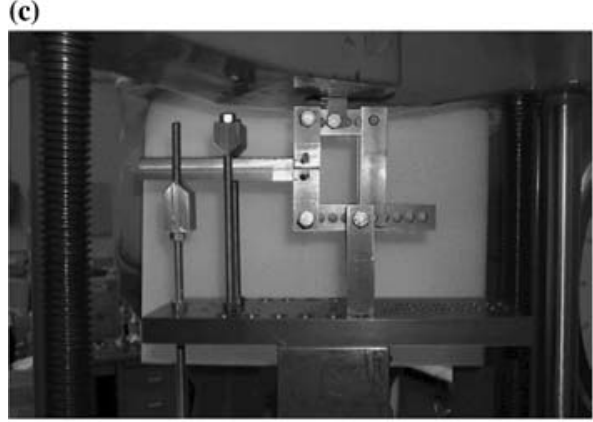

FS Jig (mixed mode, $\psi=48^{\circ}$ )

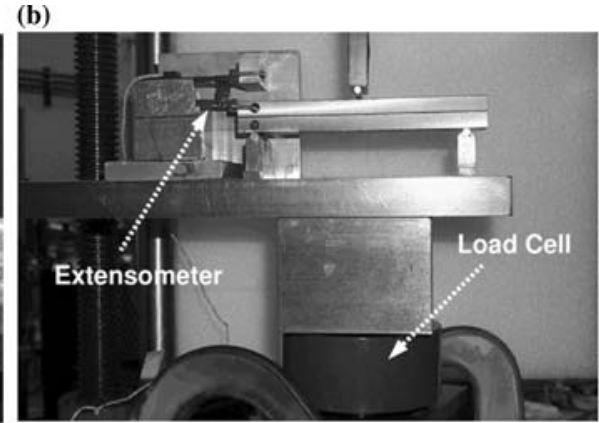

ENF (mode II, $\psi=90^{\circ}$ )

(d)

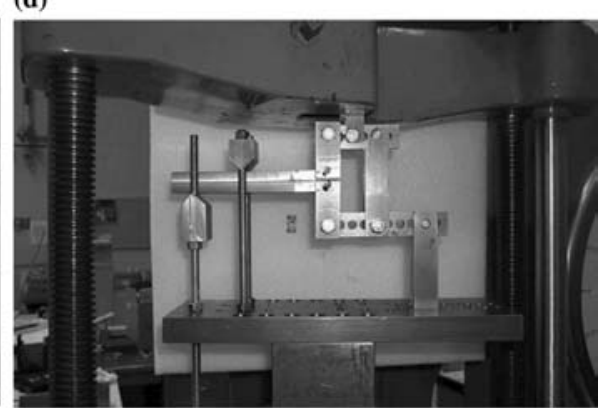

FS Jig (mixed mode, $\psi=75^{\circ}$ )

Figure 4. Experimental set-ups.

(DCB) test for mode I (opening mode) and the end-notch-flexure (ENF) test for mode II (sliding, or shear, mode) are shown in Figure 4(a) and (b), respectively. For mixed modes between pure mode I and pure mode II, a FS fixture was used (Fernlund and Spelt, 1994a, b; Papini et al. 1994). Figure 4(c) and (d) show two set-ups corresponding to two different mode mixities, respectively. 


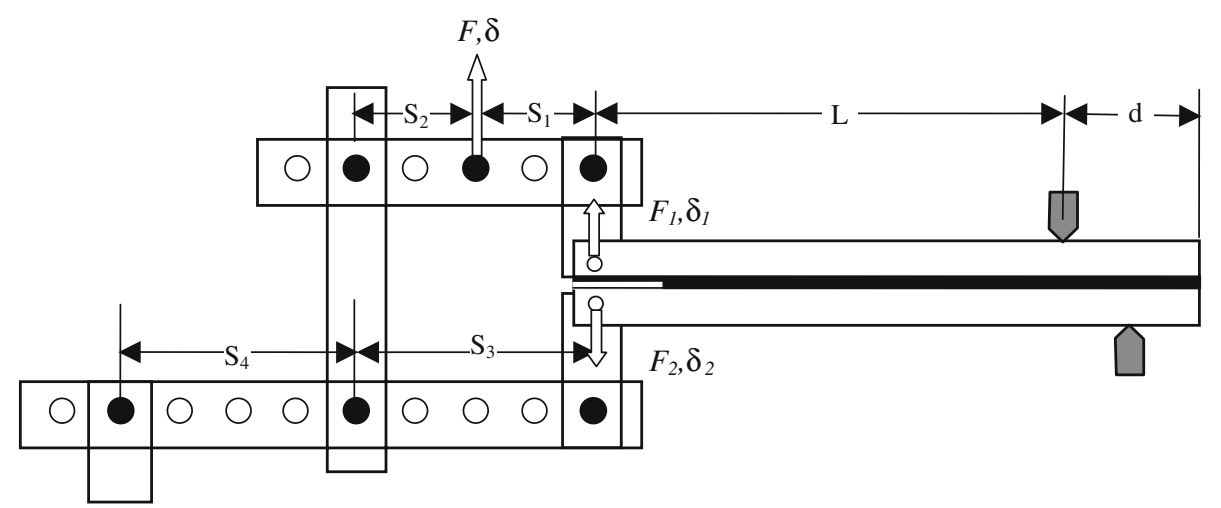

Figure 5. Schematic of the load jig proposed by Fernlund and Spelt.

Table 2. Details of load ratios for the tests.

\begin{tabular}{lll}
\hline $\begin{array}{l}\text { Phase angle, } \\
\Psi\left({ }^{\circ}\right)\end{array}$ & Load ratios & \\
\hline 0 & $F_{1}=F$ & $F_{2}=-F$ \\
48 & $F_{1}=\frac{3 F}{5}$ & $F_{2}=-\frac{F}{10}$ \\
75 & $F_{1}=\frac{F}{2}$ & $F_{2}=\frac{3 F}{14}$ \\
90 & $F_{1}=\frac{F}{4}$ & $F_{2}=\frac{F}{4}$ \\
\hline
\end{tabular}

The FS loading fixture consists of a link-arm system which allows the forces, $F_{1}$ and $F_{2}$, acting on the upper and lower adherends of the test specimen, respectively, to be varied by altering the jig geometry. $F_{1}$ and $F_{2}$ can be obtained using equilibrium of the link-arm system as

$$
\begin{aligned}
& F_{1}=F\left(1-\frac{s_{1}}{s_{3}}\right) \\
& F_{2}=F_{1} \frac{s_{1}}{s_{2}} \frac{1}{\left(1+\frac{s_{3}}{s_{4}}\right)}
\end{aligned}
$$

where, $s_{1}, s_{2}, s_{3}$, and $s_{4}$ are defined in Figure 5. The phase angle of loading $(\psi)$ is defined as

$$
\psi=\arctan \sqrt{\frac{G_{\mathrm{II}}}{G_{\mathrm{I}}}}
$$

Table 2 summarizes the load ratios corresponding to different mode mixities of the two types of specimens. In all cases, $F$ refers to the load data recorded through a load cell installed in the experimental set-up (see Figure 5). The coupons were placed in such a way that the embedded crack was located at the interface between the adhesive layer and the lower steel adherend, as shown in Figure 5.

The critical value of strain energy release rate $\left(G_{\mathrm{IC}}\right.$ and $\left.G_{\mathrm{IIC}}\right)$ was calculated through VCCT corresponding to critical forces measured from the tests. The fracture 


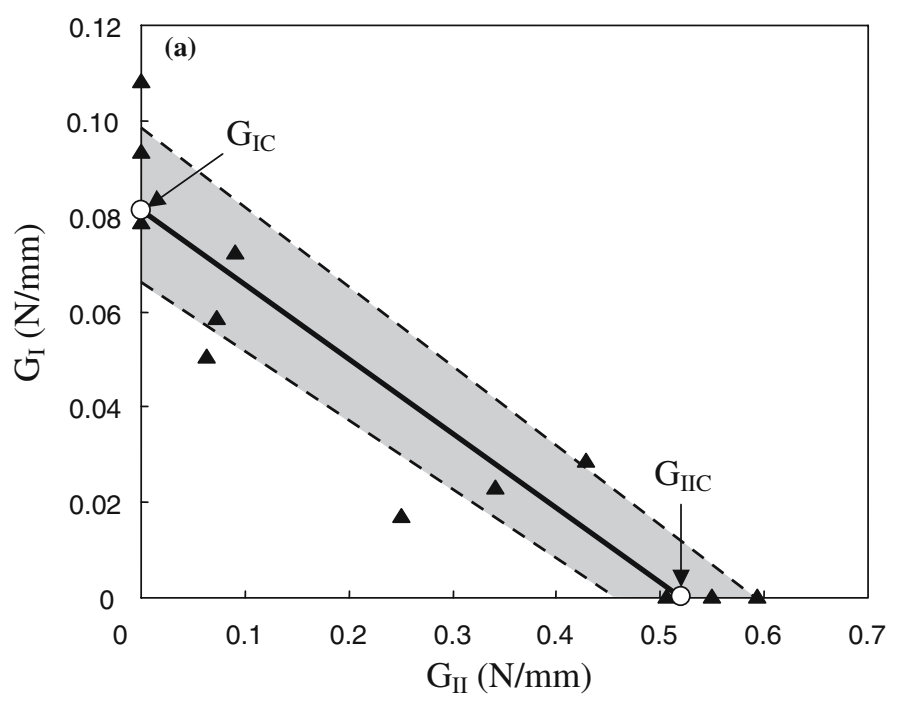

Fracture envelope in Gi vs. GII plane

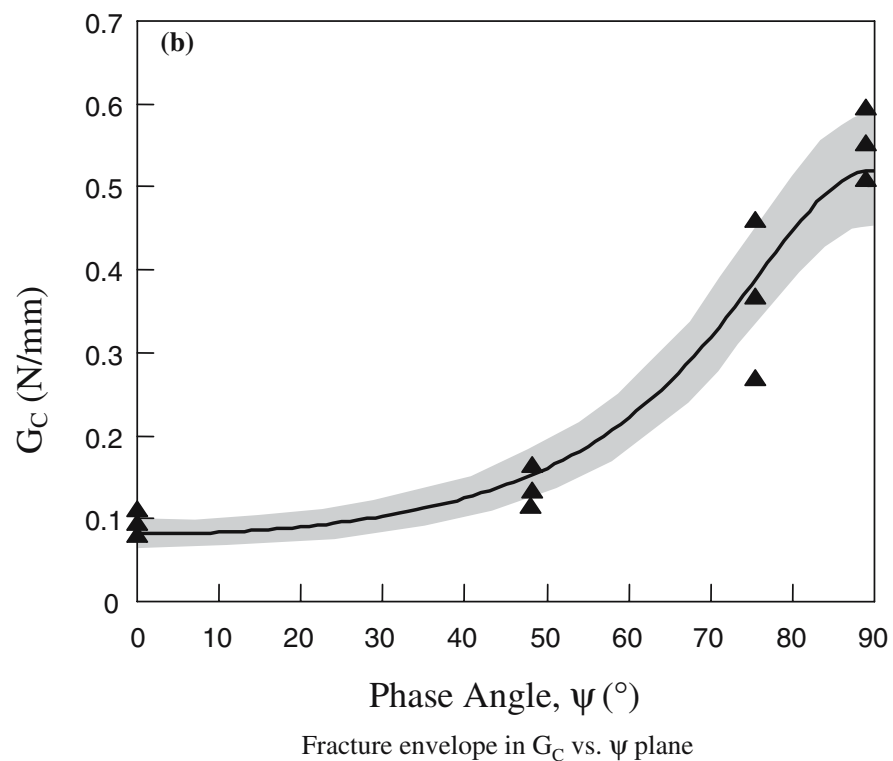

Figure 6. Fracture envelope for the adhesive/steel interface. (a) Fracture envelope in $G_{\mathrm{I}}$ vs. $G_{\text {II }}$ plane. (b) Fracture envelope in $G_{\mathrm{C}}$ vs. $\psi$ plane.

envelope can be represented by a line in the first quadrant of the $G_{\text {IC }}$ vs. $G_{\text {IIC }}$ plane, see Figure 6(a). Assuming a linear relation (Reeder and Crews, 1990), we have

$$
\frac{G_{\mathrm{I}}}{G_{\mathrm{IC}}}+\frac{G_{\mathrm{II}}}{G_{\mathrm{IIC}}}=1.0
$$

$G_{\text {IC }}$ and $G_{\text {IIC }}$ are obtained through a linear regression.

Alternatively, the fracture envelope can also be represented in the $G_{C}$ vs. $\psi$ plane. Since the total $G_{\mathrm{C}}\left(G_{\mathrm{C}}=G_{\mathrm{IC}}+G_{\mathrm{IIC}}\right)$ and $\psi$ are defined in Equation (7), the $G_{\mathrm{C}}$ vs. $\psi$ corresponding to Equation (8) is 


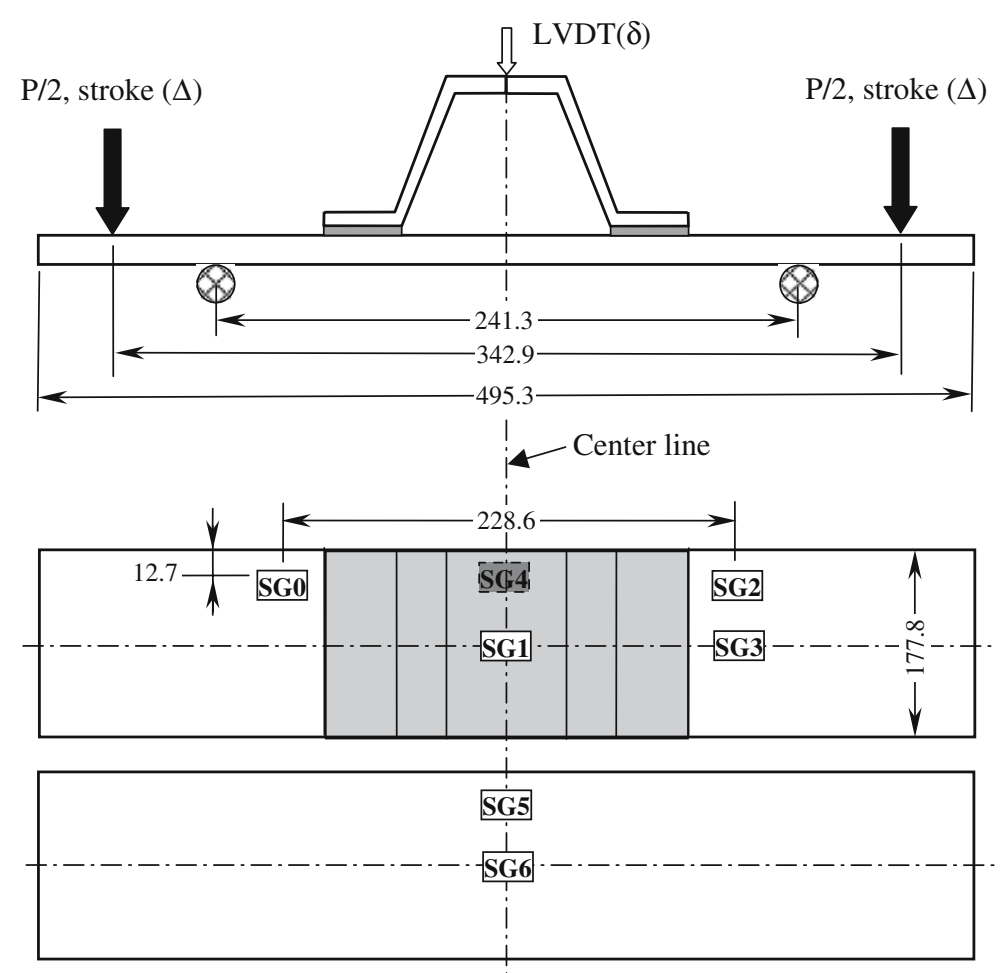

Figure 7. Notations and dimensions (mm).

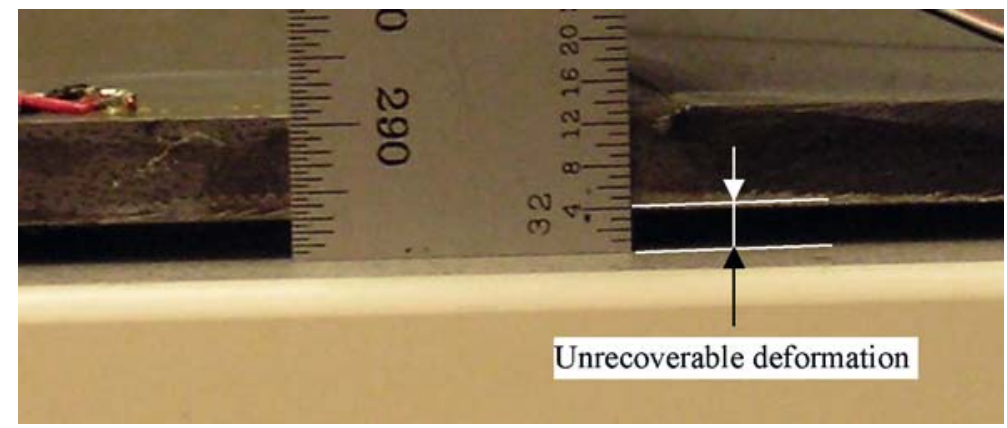

Figure 8. The unrecoverable deformation of the steel substrate after unloading.

$$
G_{\mathrm{C}}=\frac{G_{\mathrm{IC}} G_{\mathrm{IIC}}}{G_{\mathrm{IC}} \sin ^{2} \psi+G_{\mathrm{IIC}} \cos ^{2} \psi}
$$

Figure 6(b) shows the fracture envelope curve obtained from Equation (9) which qualitatively agrees with available data obtained by others (Wang and Suo, 1990; Swaden et al., 2002; Banks-Sills and Schwartz, 2002). Some researchers suggest a universal curve for $G_{\mathrm{C}}$ vs. $\psi$. This universal curve may correspond to a linear relation in the $G_{\text {IC }}$ vs. $G_{\text {IIC }}$ plane. 


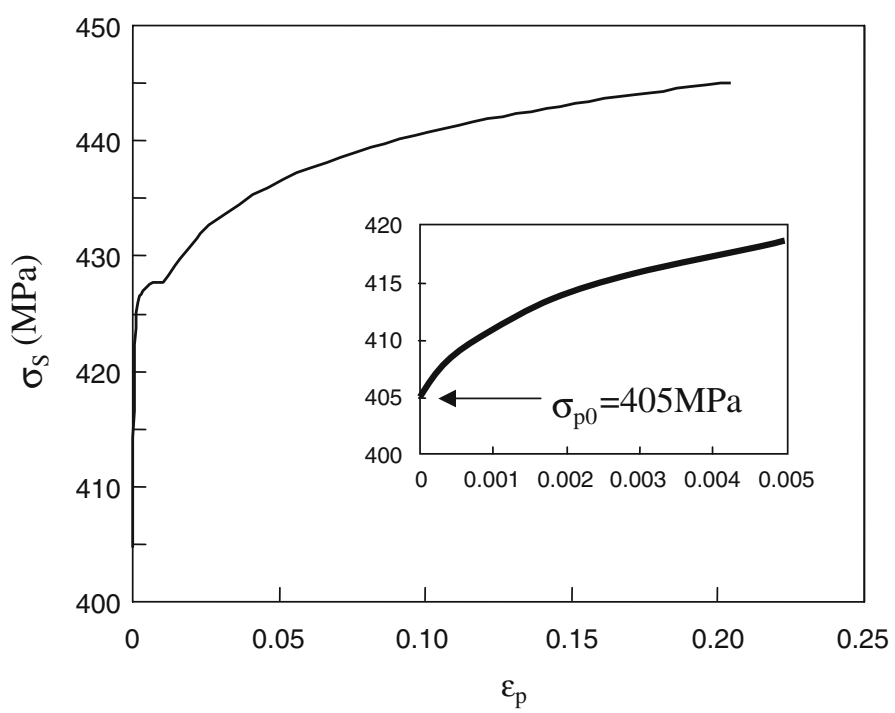

Figure 9. The plastic material behavior for steel used in the FEA model.

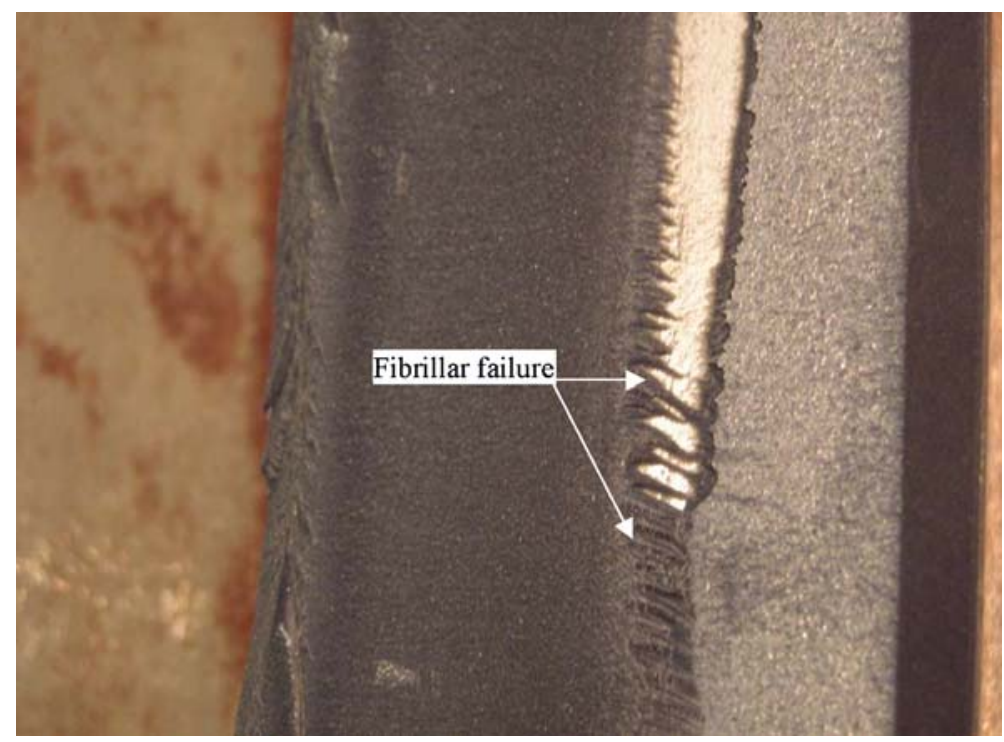

Figure 10. Ductile adhesive failure in the form of fibrillar structures.

\section{Failure analysis}

\subsection{Description of the hat Structure}

Figure 7 shows the load application point, the support positions and the strain gage locations of the full scale structural tests conducted at the Oak Ridge National Laboratories (ORNL). The LVDT's (using symbol " $\delta$ ") recorded displacement at the top surface of the hat. All LVDT's are placed to measure displacements at the top of the hat, along the spanwise centerline; the chordwise "center" LVDT is positioned at the center of the hat, the "front" and "back" LVDTs are at distances of $25.4 \mathrm{~mm}$ from 


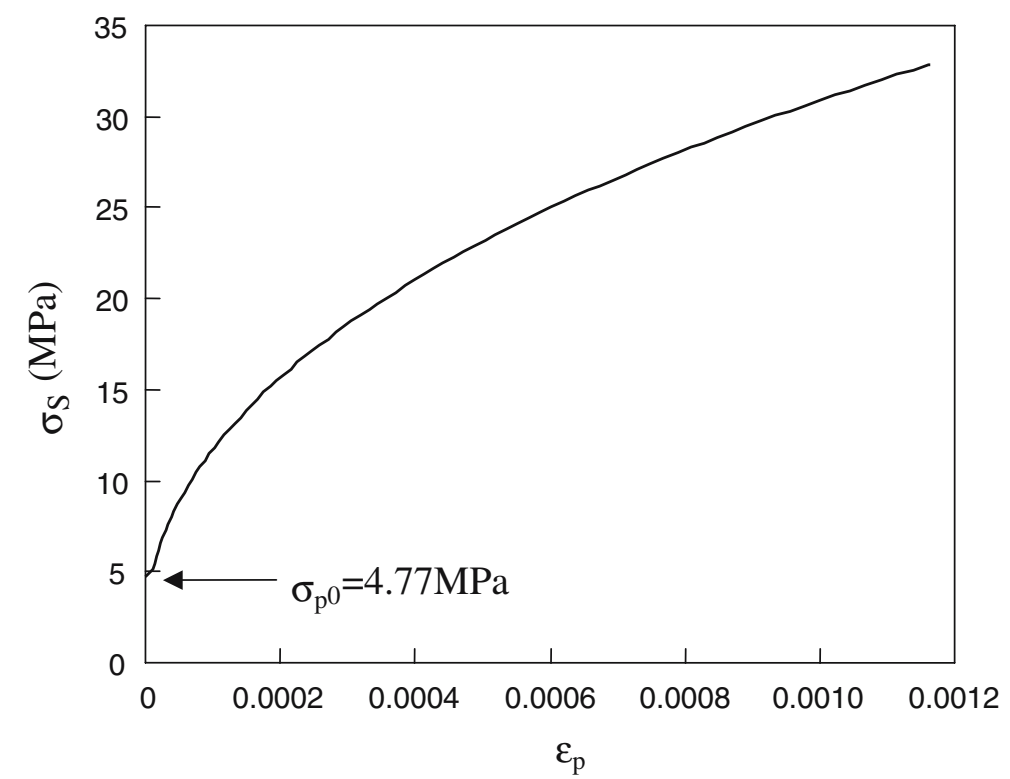

Figure 11. The plastic material behavior for the adhesive used in the FEA model.
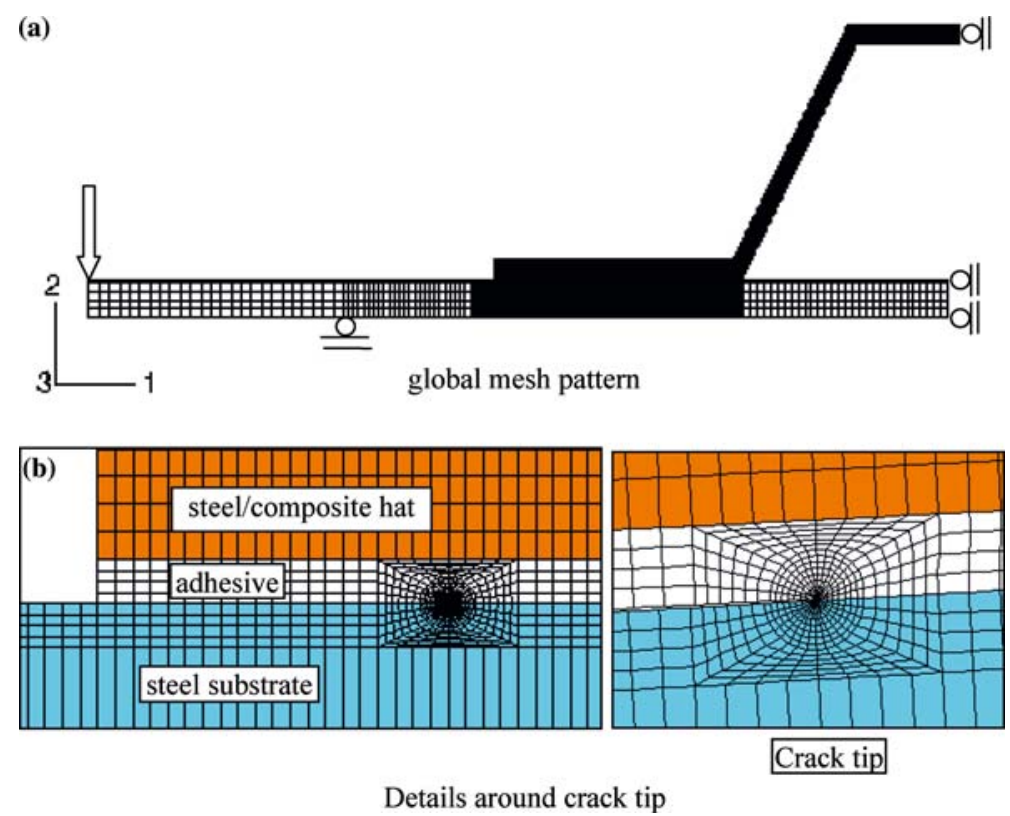

Figure 12. FEA mesh for the hat structure (plane strain model). (a) global mesh pattern, (b) details around crack tip.

one edge (or $63.5 \mathrm{~mm}$ from the middle). The travel of the loading points is noted as stroke of the machine (using symbol " $\Delta$ "). Seven strain gages were mounted on each specimen. They can be gathered as three groups based on the locations: on the hat side of the substrate (Group 1: SG0, SG2, SG3 and SG4), on top of the hat (Group 2: SG1) and on the bottom side of the substrate. (Group 3: SG5 and SG6). The 


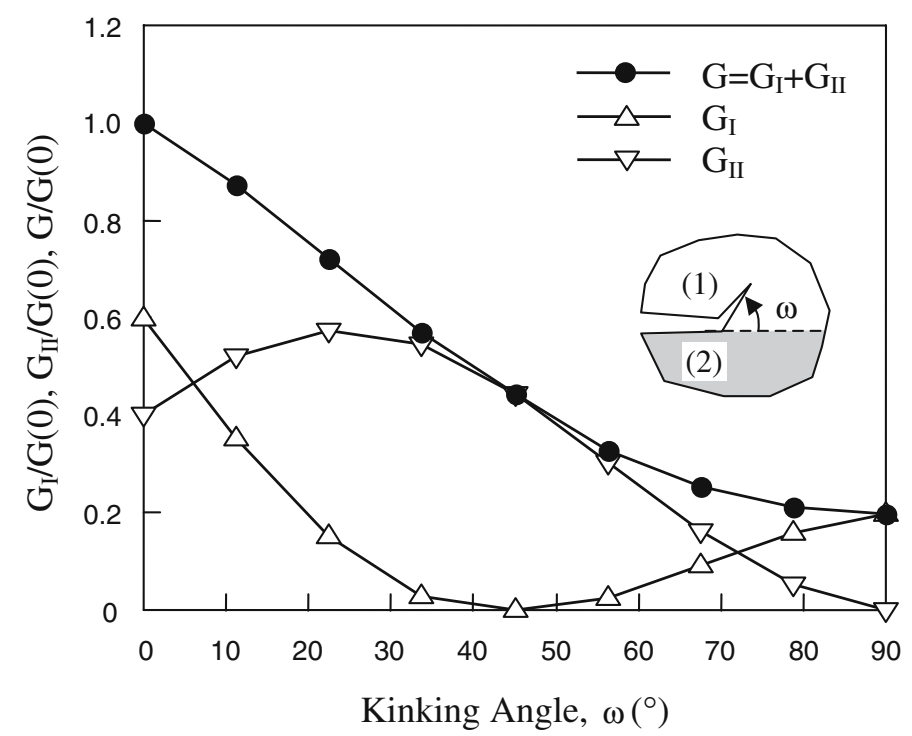

Figure 13. Strain energy release rate distribution around the crack tip for the steel hat.

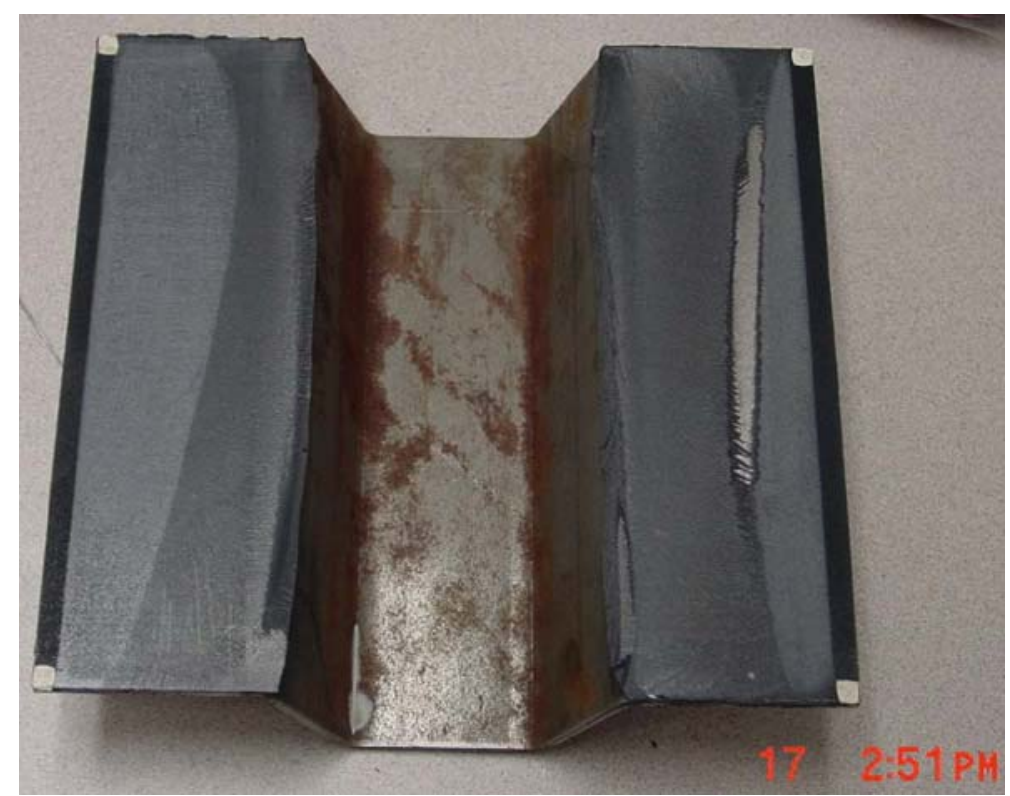

Figure 14. Fractured surfaces of the steel hat. The two narrow darker bands at the edges are the embedded starter cracks.

loading points and the support points consist of $25.4 \mathrm{~mm}$ rollers, placed $241.3 \mathrm{~mm}$ and $342.9 \mathrm{~mm}$ apart. The hat side of the specimen was in tension during the test.

Post test examination revealed permanent and unrecoverable deformation of the steel substrate, as shown in Figure 8. This is a structural level deformation due to bending. Therefore, the steel should be considered to have been stressed into the plastic regime. In the elastic range, the Young's modulus and Poisson's ratio of the 


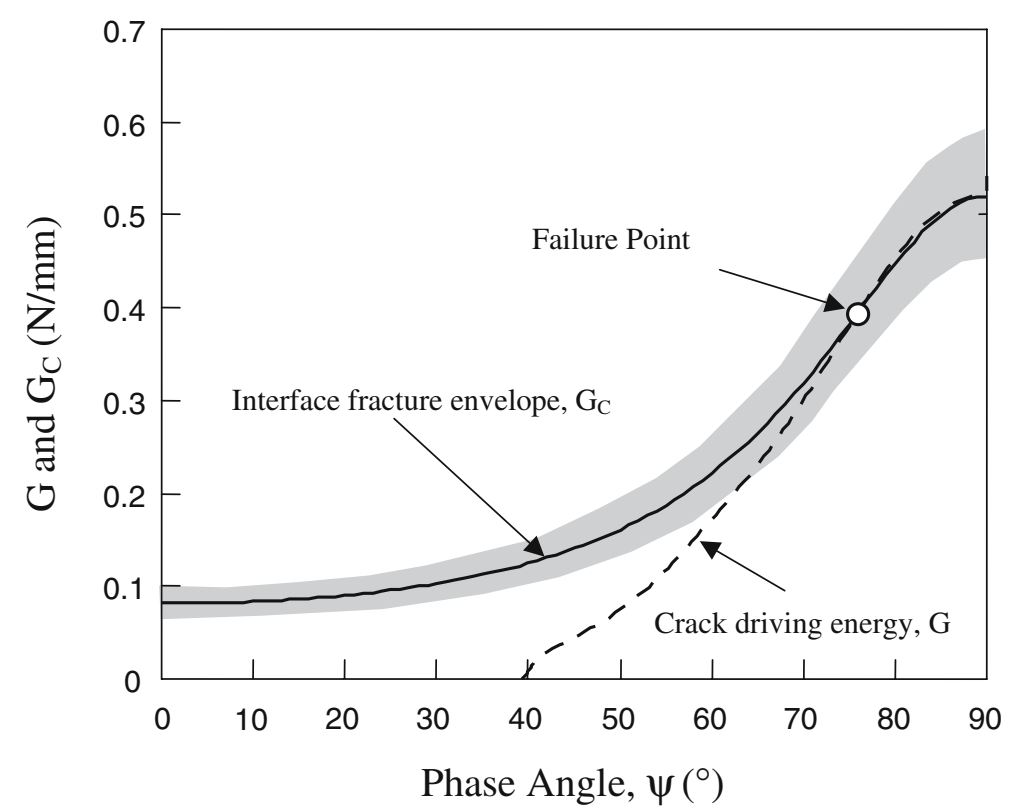

Figure 15. Failure analysis in $G_{\mathrm{C}}$ vs. $\psi$ plane for the steel hat.

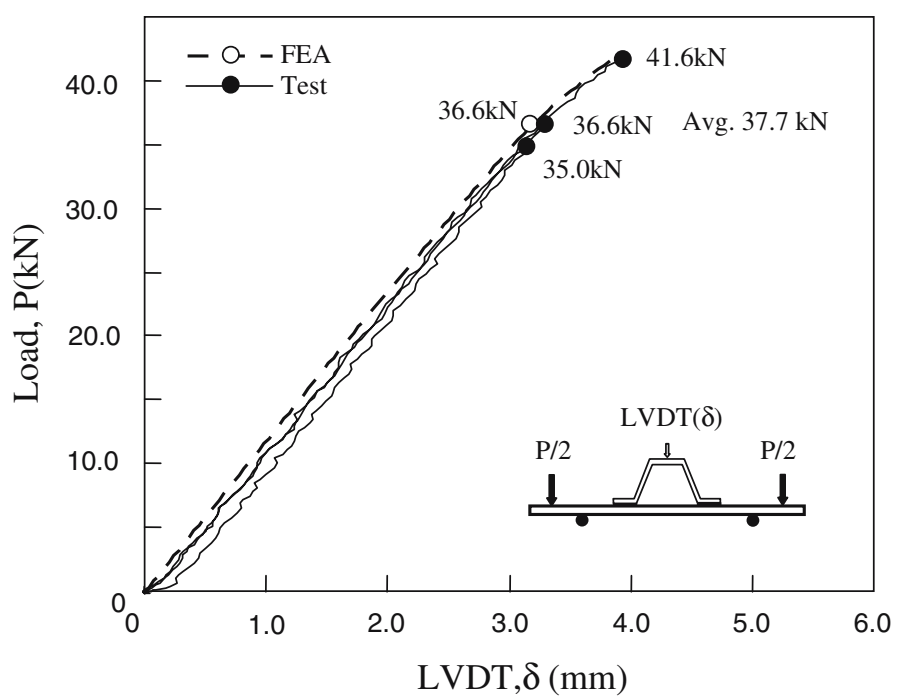

Figure 16. Predicted and measured $P$ vs. $\delta$ curves for the steel hat.

steel are $207 \mathrm{GPa}$ and 0.285 , respectively. The plastic behavior is shown in Figure 9 through the plastic strain vs. plastic stress curve. The initial yield stress $\sigma_{\mathrm{y} 0}$ was assumed to be $405 \mathrm{MPa}$.

In particular, we note the work of Chai $(1986,1993)$, who performed measurements on adhesive joints as a function of adhesive thickness and showed that $G$ values can and will depend in a non-monotonic manner on adhesive thickness. In the present work, there is evidence of ductile adhesive failure in the formation of fibrillar structures within the adhesive (cohesive fracture), see Figure 10. To explain this 

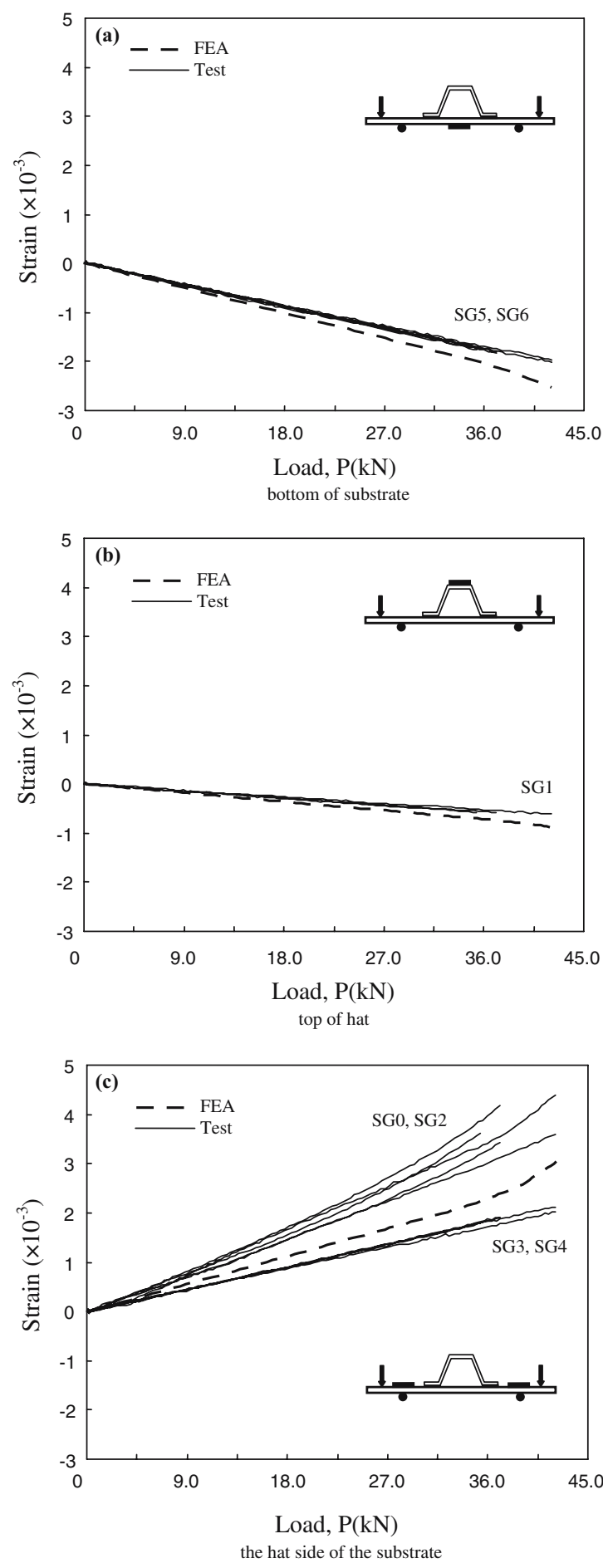

Figure 17. Predicted and measured strains at different locations on the steel hat (a) bottom of substrate, (b) top of hat, (c) the hat side of the substrate. 


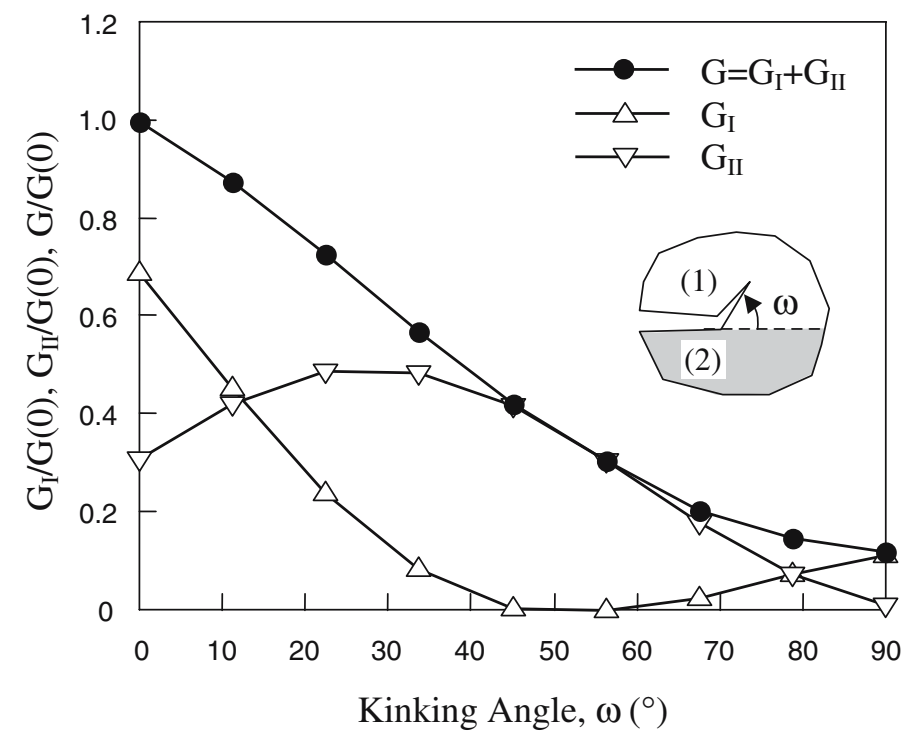

Figure 18. Strain energy release rate distribution around the crack tip for the composite hat.

behavior, the plastic behavior of the adhesive was incorporated into the stress analysis by using the stress vs. strain cures shown in Figure 11.

The dimensions of the steel substrate (steel flat) were $495.3 \times 177.8 \mathrm{~mm}$. The thickness of the steel flat was $7.75 \mathrm{~mm}$ when paired with the steel hat and $5.72 \mathrm{~mm}$ when paired with the composite hat, respectively. The adhesive was $0.645 \mathrm{~mm}$ thick. The steel hat was $3.3 \mathrm{~mm}$ thick while the composite hat was $3.4 \mathrm{~mm}$ thick. Young's modulus for the composite hat was $52.7 \mathrm{GPa}$ and Poisson's ratio was 0.44 .

The mesh used for the FEA is shown in Figure 12(a). A generalized plain strain analysis (in the 1-2 plane, across the width) is invoked. The detail around the crack tip is shown in Figure 12(b). The following criterion was used to predict the failure load:

$$
G(\psi) \geq G_{\mathrm{C}}(\psi)
$$

\subsection{Steel hat}

Three samples of steel HABS were tested. All of them failed catastrophically (sudden failure) at $41.0,36.6$ and $35.0 \mathrm{kN}$, respectively, with unstable crack growth along the interface. The average failure load was $37.7 \mathrm{kN}$. The consistency in the recorded data for the three samples is very good. With the adaptive kinking VCCT, the distribution of strain energy release rate around the crack tip at different load levels is shown in Figure 13. Based on the criterion in Xie et al. (2005), the crack was predicted to initiate at $\omega=0$, which corresponds to propagation parallel to the interface. The HABS tests confirmed this prediction, as indicated in Figure 14.

Figure 15 shows the failure analysis based on the criterion in Equation (10). With the adaptive VCCT interface element, we keep track of the total $G$ value and incrementally increase the load (or displacement) until the total $G$ value and the 


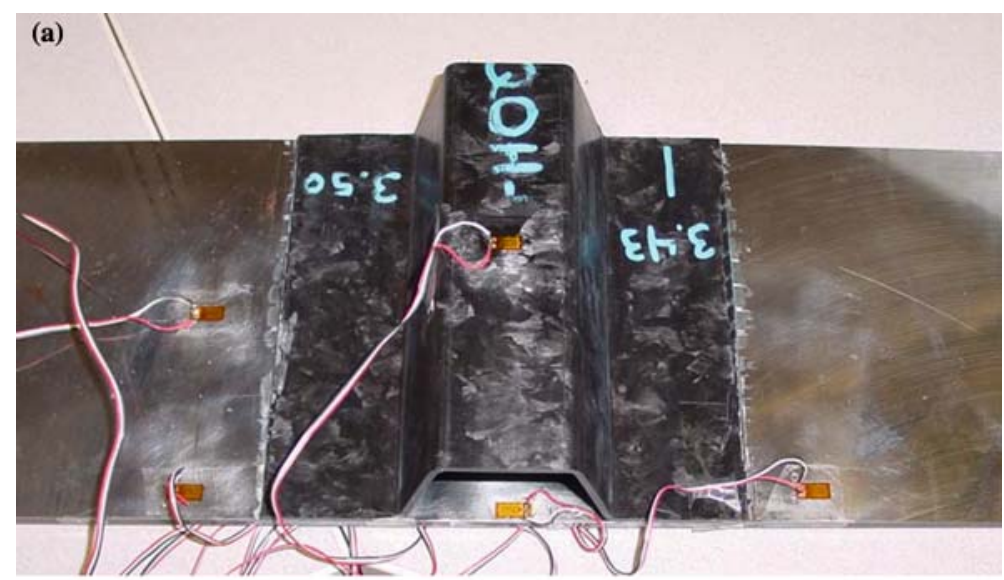

Before test
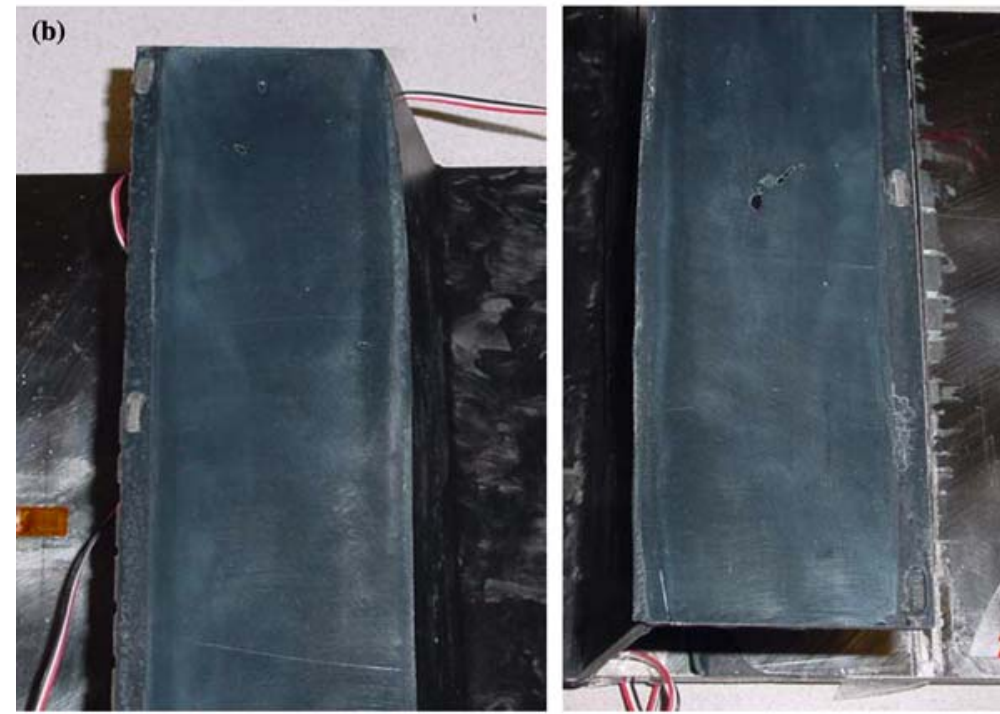

\section{fracture surface}

Figure 19. Composite hat. (a) before test, (b) fracture surface.

corresponding mode mixity exceed the measured fracture envelope $\left(G_{\mathrm{C}}\right.$ vs. $\left.\psi\right)$. At this point, the value of load $P$ is noted as $36.6 \mathrm{kN}$ which is close to the average test value $(37.7 \mathrm{kN})$. The relative error is $-3 \%$. The predicted $P$ vs. $\delta$ curve is shown in Figure 16. The slope and the shape of this curve, as well as the failure load, match well with the measured test data.

The present FEA model was further validated by comparing strains. Figure 17(a) compares the strains at the bottom side of the substrate. The measured data shows good consistency among different samples and the agreement with the predicted FEA simulation is very good. Figure 17(b) shows a comparison of strain measured at the top of the hat. The consistency among tests and agreement between test and simulation are very good. 


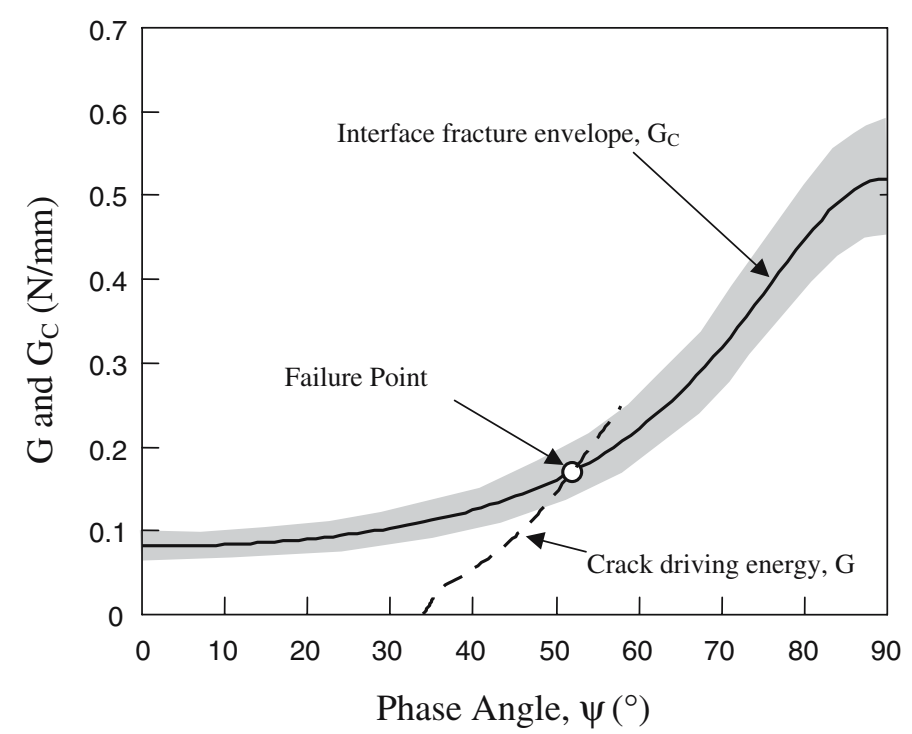

Figure 20. Failure Analysis in $G_{\mathrm{C}}$ vs. $\psi$ plane for the composite hat.

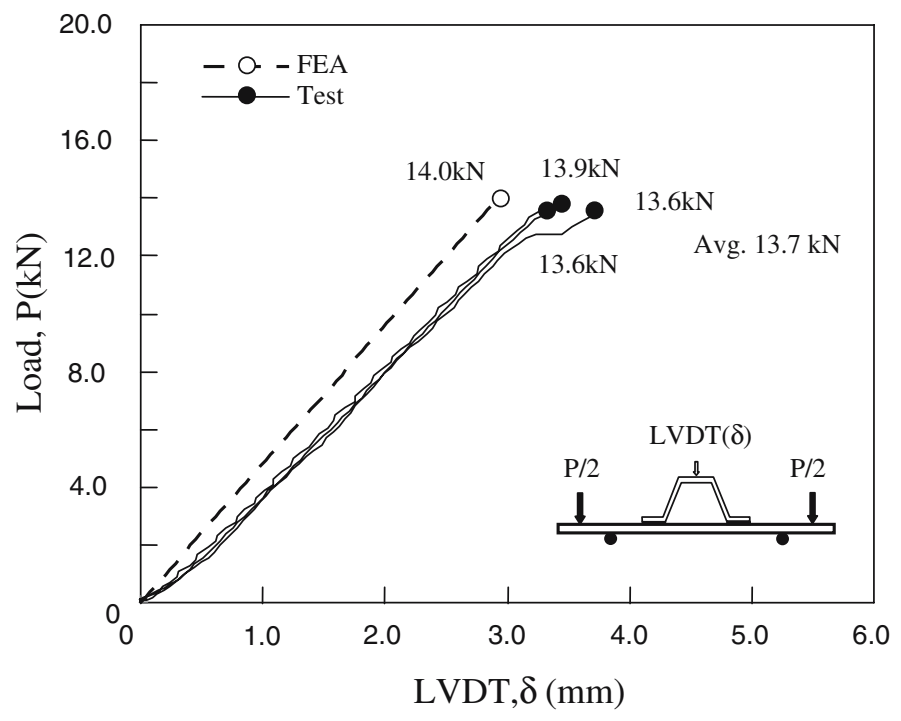

Figure 21. Predicted and measured $P$ vs. $\delta$ curves for the composite hat.

On the hat side of the substrate, the hat deformation can induce 3D and localized effects. These effects are attributed to the different curves obtained from different specimens (see Figure 17(c)). The simulated strain curve is among the test curves (bounded by the various specimen results) which is reasonable and within engineering accuracy.

\subsection{Composite Hat}

Three samples of the composite HABS were tested. All these samples failed gently (not sudden failure) without any significant load drop observed from load vs. 

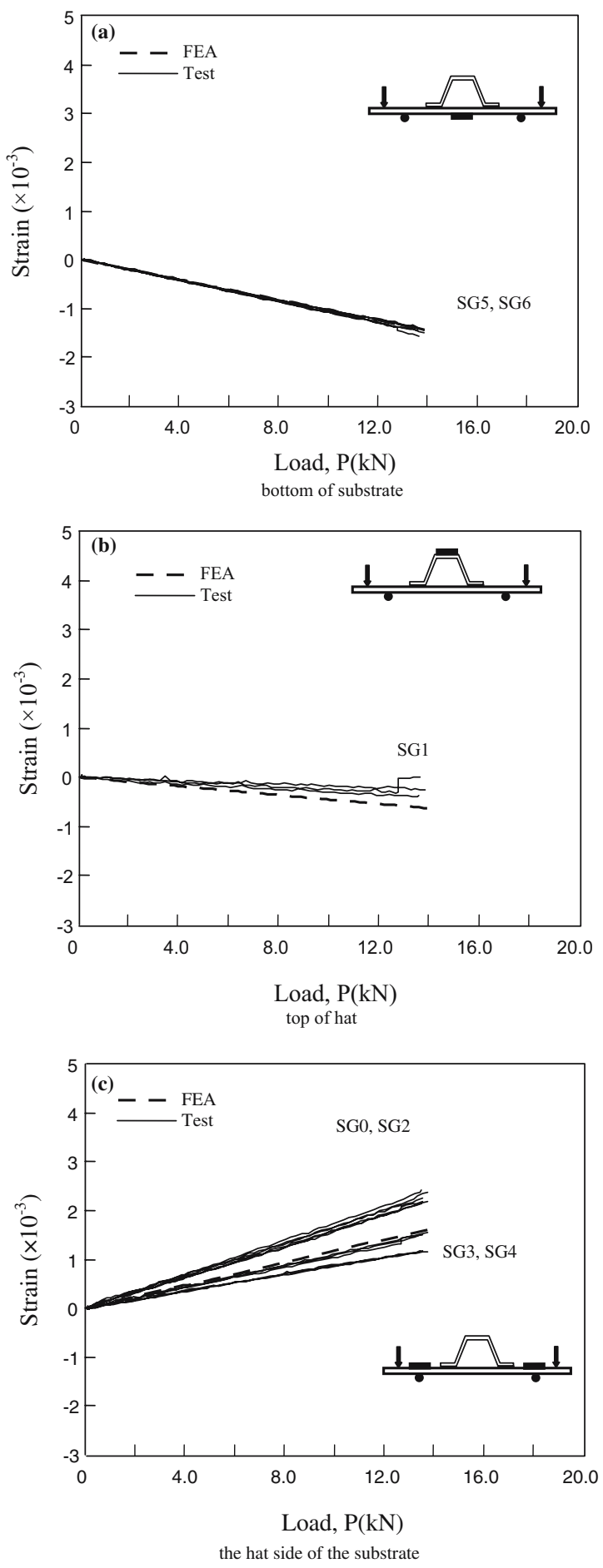

Figure 22. Predicted and measured strains at different locations of the composite hat. (a) bottom of substrate, (b) top of hat, (c) the hat side of the substrate. 
LVDT curves. The specimen failed in the form of interface separation. The Hat was separated from the substrate at failure. The failure loads from three samples are 13.9, 13.6 and $13.6 \mathrm{kN}$, respectively. The average failure load was $13.7 \mathrm{kN}$. The consistency in the recorded data for the three samples was very good.

With the adaptive kinking VCCT, the distribution of strain energy release rate around the crack tip at different load levels is shown in Figure 18. Based on the criterion in Xie et al. (2005), the crack is predicted to initiate at $\omega=0$, parallel to the interface. The HABS test confirmed this prediction as shown in Figure 19. Figure 20 shows the failure analysis results based on the criterion in Equation (10). With the adaptive VCCT interface element, as before, the total $G$ value was monitored and the load (or displacement) was increased incrementally until the total $G$ value and the corresponding mode mixity exceeded the measured fracture envelope $\left(G_{\mathrm{C}}\right.$ vs. $\psi$ ). At this point, the value of load $\mathrm{P}$ was approximately $14.0 \mathrm{kN}$ which is close to the average test value $(13.7 \mathrm{kN})$. The relative error was $+2 \%$. The predicted $P$ vs. $\delta$ curve is shown in Figure 21. The failure load agrees well between prediction and test. The simulated stiffness of the composite hat is higher than what was indicated in test data, while for the steel hat the agreement was good (see Figure 16). Since the composite used has randomly distributed chopped fibers, its mechanical properties variation is expected to be larger than in steel. The input mechanical properties, which assume linear elastic behavior and isotropy for the composite, are based on coupon level tensile tests, which may have properties that are slightly different from those that correspond to the hats.

The present FEA model was further validated by comparing strains. Figure 22(a) compares the strains at the bottom side of the substrate. The measured data shows excellent consistency among samples and the agreement with the predicted FEA simulation is very good. Figure 22(b) shows a comparison of strains at the top of the hat. The consistency among tests and agreement between test and simulation are all very good. As before, aside from minor deviations between tests of the same structure due to $3 \mathrm{D}$ and localized effects of the hat deformation, the simulated strain prediction falls within the test results and the agreement between prediction and experiment is very good as shown in Figure 22(c).

\section{Conclusions}

Full size hat stiffened adhesively bonded structures were successfully tested to failure. The average failure loads for the steel and composite hat structures are 37.7 and $13.7 \mathrm{kN}$, respectively. An adaptive VCCT was developed and validated to calculate strain energy release rates. The fracture envelope from laboratory scale joint coupons was measured by using the Fernlund-Spelt test fixture. By computing the strain energy release rate distribution around the crack tip of the hat stiffened structure, the crack was predicted to extend along the interface which was confirmed by the structural level tests. The total strain energy release rate criterion was employed to predict the failure load. The predicted failure loads are $36.6 \mathrm{kN}$ for the steel hat and $14.0 \mathrm{kN}$ for the composite hat-stiffened structure, respectively. They agree very well with test data $(-3 \%$ and $+2 \%)$. The analysis tools developed and presented here provide a systematic procedure for the design and analysis of hat-stiffened adhesively bonded structures. 


\section{Acknowledgements}

The authors wish to thank the DOE program management team and the Board and staff of the Automotive Composites Consortium. This work was sponsored by the Automotive Composites Consortium and the U. S. Department of Energy, Office of Energy Efficiency and Renewable Energy, FreedomCAR and Vehicle Technologies, Automotive Lightweight Materials Program, under Cooperative Agreement number DE-FC05-95OR22363. DX, JC and AMW wish to thank the Aerospace Engineering Department at the University of Michigan. We gratefully acknowledge Ronny Lomax and Don Erdman from ORNL for supplying the HABS specimens used in the study.

\section{References}

Atluri, S.N. (1997). Structural Integrity and Durability. Tech Science Press, Forsyth, GA.

Banks-Sills, L. and Schwartz, J. (2002). Fracture testing of Brazilian disk sandwich specimens. International Journal of Fracture 118, 191-209.

Bao, G., Ho, S., Suo, Z. and Fan, B. (1992). The role of material orthotropy in fracture specimens for composites. International Journal of Solids and Structures 9, 1105-1116.

Chai, H. (1986). On the correlation between the Mode I failure of adhesive joints and laminated composites. Engineering Fracture Mechanics 24, 413-431.

Chai, H. (1993). Observation of deformation and damage at the tip of cracks in adhesive bonds loaded in shear and assessment of a criterion for fracture. International Journal of Fracture 60, 311-326.

Chung, J. and Waas, A.M. (2002, August). Computational and experimental schemes for modeling adhesively bonded structures, Phase I final report submitted to Joining Work Group/ACC-USCAR.

Fernlund, G. and Spelt, J.K. (1994a). Mixed-mode fracture characterisation of adhesive joints. Composites Science and Technology 50, 441-449.

Fernlund, G. and Spelt, J.K. (1994b). Mixed-mode energy release rates for adhesively bonded beam specimens. Journal of Composites Technology and Research 16, 234-243.

Hutchinson, J.W. and Suo, Z. (1992). Mixed-mode cracking in layered materials. Advances in Applied Mechanics 29, 63-191.

Krueger, R. The virtual crack closure technique: history, approach and applications. NASA/CR-2002211628.

Papini, M. Fernlund, G. and Spelt, J.K. (1994). The effect of geometry on the fracture of adhesive joints. International Journal of Adhesion Adhesives 14, 5-13.

Reeder, J.R. and Crews, J.H. (1990). Mixed-mode bending method for delamination testing. AIAA Journal 28, 1270-1276.

Rybicki, E.F. and Kanninen, M.F. (1977). A finite element calculation of stress intensity factors by a modified crack closure integral. Engineering Fracture Mechanics 9, 931-938.

Shivakumar, K.N. Tan, P.W. and Newman, Jr J.C. (1988). A virtual crack-closure technique for calculating stress intensity factors for cracked three dimensional bodies. International Journal of Fracture 36, R43-R50.

Suo, Z. and Hutchinson, J.W. (1990). Interface crack between two elastic layers. International Journal of Fracture 43, 1-18.

Swadener, J.G. Liechti, K.M. and Liang, Y.M. (2002). Shear induced toughening in bonded joints: experiments and analysis. International Journal of Fracture 114, 113-132.

Wang, J.S. and Suo, Z. (1990). Experimental determination of interfacial toughness curves using Brazilnut-sandwiches. Acta Metallurgica Et Materialia 38, 1279-1290.

Xiao, X.R., Foss, P.H. and Schroeder, J.A. (2004a). Stiffness prediction of the double lap shear joint. Part 1: Analytical solution. International Journal of Adhesion and Adhesives 24, 229-237.

Xiao, X.R., Foss, P.H. and Schroeder, J.A. (2004b). Stiffness prediction of the double lap shear joint. Part 2: Finite element modeling. International Journal of Adhesion and Adhesives 24, 239-246.

Xie, D. and Biggers, S.B. (accepted). Strain energy release rate calculation for a moving crack front of arbitrary shape based on virtual crack closure technique. Engineering Fracture Mechanics. 


\section{De Xie et al.}

Xie, D. and Biggers, S.B. (Submitted). Progressive crack growth analysis using interface element based on the virtual crack closure technique. Finite Elements in Analysis and Design.

Xie, D., Waas, A.M., Shahwan, K.W., Schroeder, J.A. and Boeman, R.G. (2004). Computation of Energy Release Rates for kinking cracks based on virtual crack closure technique. Computer Modeling in Engineering \& Sciences 6, 515-524.

Xie, D., Waas, A.M., Schroeder, J.A. Shahwan, K.W. and Boeman, R.G. (in press). Fracture Criterion for kinking cracks in triple material adhesively bonded joints under mixed mode loading. Engineering Fracture Mechanics 72, 2487-2540. 